\title{
Effects of different management practices on the soil-water balance and crop yield for improved dryland farming in the Chinese Loess Plateau
}

\author{
Ke Jin ${ }^{\mathrm{a}, *}$, Wim M. Cornelis ${ }^{\mathrm{b}, * *}$, Wouter Schiettecatte ${ }^{\mathrm{b}}$, Junjie $\mathrm{Lu}^{\mathrm{c}}$, \\ Yuqing Yao ${ }^{\mathrm{c}}$, Huijun $\mathrm{Wu}^{\mathrm{a}}$, Donald Gabriels ${ }^{\mathrm{b}}$, Stefaan De Neve ${ }^{\mathrm{b}}$, \\ Dianxiong Cai ${ }^{\mathrm{a}}$, Jiyun Jin ${ }^{\mathrm{a}}$, Roger Hartmann ${ }^{\mathrm{b}}$ \\ ${ }^{a}$ Agricultural Resources and Regional Planning Institute, Chinese Academy of Agricultural Sciences, \\ Key Laboratory of Plant Nutrition \& Nutrient Cycling, MOA 100081, PR China \\ ${ }^{\mathrm{b}}$ Department of Soil Management and Soil Care, International Centre for Eremology, Ghent University, \\ Coupure Links 653, B-9000 Ghent, Belgium \\ ${ }^{\mathrm{c}}$ Luoyang Academy of Agricultural Sciences, 5 Jun Min Road, Anle, Luoyang, PR China
}

Received 12 December 2006; received in revised form 13 April 2007; accepted 5 May 2007

\begin{abstract}
Field experiments were carried out to study the effects of different soil management practices on the water balance, precipitation use efficiency (PUE), and crop yield (i.e. winter wheat and peanut) on a loess soil near Luoyang (east edge of the Chinese Loess Plateau, Henan Province, China). Field plots were set up in 1999 including following soil management practices: subsoiling with mulch (SS), no-till with mulch (NT), reduced tillage (RT), two crops per year (i.e. winter wheat and peanut, TC), and a conventional tillage control (CT). The field plots were equipped to monitor all components of the soil-water balance except evapotranspiration, which was computed by solving the water balance equation. The results showed that although soil management had smaller influence on the magnitude of the water balance components than did precipitation variations, small influences of the applied soil management practices on water conservation during the fallow period can greatly affect winter wheat yield. SS increased consistently precipitation storage efficiency (PSE) and PUE over the 5 years compared to CT except during the wettest year. NT also had a noticeable effect on postharvest water storage during the fallow period; however, the influence on yield of NT depended on the amount of precipitation. TC lowered the winter wheat yield mainly due to the unfavorable soil moisture conditions after growing peanut in summer; however, the harvested peanut gained an extra profit for the local farmer. No matter which kind of soil management practices was adapted, PSE never exceeded $41.6 \%$, which was primarily attributed to high evapotranspiration. From data of five consecutive agricultural years between 2000 and 2005, it could be concluded that SS resulted in the highest PSE, PUE and crop yield. TC also showed promising results considering the economic value of the second crop. NT performed slightly less as SS. CT gave intermediate results, whereas RT was the worst alternative.
\end{abstract}

(C) 2007 Elsevier B.V. All rights reserved.

Keywords: Dryland; Rainfed agriculture; Soil management practices; Water balance; Water conservation; Winter wheat

Abbreviations: CT, conventional tillage; $D$, drainage; ET, evapotranspiration; $I$, irrigation; $L_{\mathrm{i}}$, lateral inflow; $L_{\mathrm{o}}$, lateral outflow; NT, no tillage; $\mathrm{OC}$, organic carbon; $P$, precipitation; $P_{\mathrm{f}}$, precipitation during fallow period; $P_{\mathrm{g}}$, precipitation during growing period; PSE, precipitation storage efficiency; $R$, runoff; RT, reduced tillage; $S$, water storage; $S_{\mathrm{i}}$, water storage in the beginning of the crop year; $S_{\mathrm{o}}$, water storage at the time of winter wheat sowing; $S_{\mathrm{e}}$, water storage at the end of the crop year; SS, subsoiling; TC, two-crop rotation; PUE, precipitation use efficiency

* Corresponding author. Tel.: +8610 68918665x604; fax: +86 1068915161 .

** Corresponding author.

E-mail addresses: kjin@ppi.caas.ac.cn, ke_jin@hotmail.com (K. Jin), wim.cornelis@UGent.be (W.M. Cornelis). 


\section{Introduction}

Satisfactory crop production under semi-humid conditions will have a major impact on maintaining the economic viability of the major crop production area of the Chinese Loess Plateau. Limited crop available water and soil erosion are major factors constraining agricultural production in this area. Luk and Huang (1991) estimated the average erosion rate of cultivated land in the Chinese Loess Plateau at 60 tonnes ha ${ }^{-1}$ year $^{-1}$. Inappropriate conventional farming practices were identified as the main causes for land degradation (Wang et al., 2006). These include practices such as intensive ploughing and the routine removal of crop residues, which are the primary factors leading to soil erosion. Farmers therefore need to manage their resources and adopt appropriate tillage practices without removing residues in order to effectively store and use the limited amount of precipitation for crop production and to control soil erosion.

In the Loess Plateau of China, winter wheat (Triticum aestivum L.) is the most commonly grown crop and occupies $44 \%$ of the cultivated area. However, wheat productivity is seriously curtailed by water shortage and nutrient deficiency as a result of severe water loss and soil erosion. Since rainwater is the sole water resource for dryland farming in the Loess Plateau, rainfed crop production thus depends strongly on both the amount and distribution of rain, and efficient capture and retention of precipitation is essential to maximize crop growth. The Chinese Loess Plateau is governed by a continental monsoon temperate climate. The rainfall often is not only inadequate but also, over $60 \%$ of annual precipitation occurs in the 3 months between July and September in the form of storms. Winter wheat (T. aestivum L.) in the Loess Plateau is harvested at the end of May and sown in late September. Therefore, uneven distribution of rainfall and the high evaporative demand result in an unbalance between the crop water requirements and the water supply, leading to water stress and decrease in grain yield.

The conventional tillage methods in the Chinese Loess Plateau are based on the principle that all crop residues are removed from the fields before a new crop is sown or planted in a fine, loose and smooth soil (Cai et al., 2006). The rationale behind this practice is that: weeds are well controlled and the sowing or planting operation can be done efficiently; however, the conventional farming practices are very far from being sustainable and environmentally compatible. The intensive ploughing and little use of crop residue exacerbate soil, water and nutrient losses in conventional tillage resulting in decreases in water availability, soil fertility and eventually declining crop production. The detrimental effects of drought can be modified to some extent through management options such as conservation tillage (i.e. zero tillage or reduced tillage with mulch) and by sowing early in the season. The management of soil through conservation tillage changes affects the storage of water and evaporation, and thus has a beneficial effect on conservation of rain water and on crop production (Gao et al., 1991; Cai and Wang, 2002; Huang et al., 2003; Wang et al., 2003; Huang et al., 2005, Lenssen et al., 2007). Zero tillage (Wang et al., 2006), rotations with short-season legumes (such as peanut or maize; Cornelis et al., 2004), and stubble retention (Fabrizzi et al., 2005) are being introduced as options to combat erosion and improve yields (and income) in the Loess Plateau of China and these practices are rapidly being adopted. It is estimated that over 1 million ha of farmland is now under conservation tillage in the drylands of China (McGarry, 2005). However, the productivity in the Loess Plateau still tends to be very low ( $\mathrm{Li}, 2004)$. Therefore, continued efforts are needed in dryland agriculture research in order to feed the rapidly growing population. At present, few studies have investigated the effects of various management practices on water conservation, water use and crop production with long term consecutive results in the Loess Plateau (Huang and Zhong, 2003). Furthermore, few works have been carried out to explore the possibility of changing the cropping system.

In order to develop guidelines for farmers and/or decision makers to adopt sustainable crop production, potential soil management practices under various conditions must be evaluated in terms of their effect on water conservation and yield, and on soil and nutrient losses. The objective of this study was therefore to evaluate four different soil management practices vis-àvis conventional tillage in terms of water conservation, water use and crop yield, in the eastern part of the Chinese Loess Plateau. This paper reports results from the study period 2000-2005.

\section{Materials and methods}

\subsection{Experimental design}

An experimental station aimed specifically at monitoring the impact of the conversion of conventional to conservation tillage, was set up in 1999 near the city of Luoyang (Henan province; $113.0^{\circ}$ East longitude, 
Table 1

Soil characteristics at the experimental station near Luoyang (Henan Province)

\begin{tabular}{lllllll}
\hline Depth $(\mathrm{m})$ & $0-2 \mu \mathrm{m}\left(\mathrm{g} \mathrm{kg}^{-1}\right)$ & $2-50 \mu \mathrm{m}\left(\mathrm{g} \mathrm{kg}^{-1}\right)$ & $50-2000 \mu \mathrm{m}\left(\mathrm{g} \mathrm{kg}^{-1}\right)$ & $\mathrm{CaCO}_{3}\left(\mathrm{~g} \mathrm{~kg}^{-1}\right)$ & $\mathrm{OC}\left(\mathrm{g} \mathrm{kg}^{-1}\right)$ & $\mathrm{pH}(\mathrm{KCl})$ \\
\hline $0.00-0.02$ & 143 & 748 & 109 & 113 & 6.5 & 7.7 \\
$0.02-0.30$ & 141 & 743 & 116 & 129 & 4.5 & 7.8 \\
$0.30-0.60$ & 138 & 745 & 117 & 142 & 2.0 & 7.7 \\
$0.60-0.85$ & 148 & 736 & 116 & 135 & 2.5 & 7.8 \\
$0.85-1.30$ & 140 & 745 & 115 & & \\
\hline
\end{tabular}

$34.5^{\circ}$ North latitude), in the eastern part of the Chinese Loess Plateau. In this region, the Quaternary loess has a thickness varying from 50 to $100 \mathrm{~m}$. It has a loose and porous structure with high hydraulic conductivity. The soil in the study area was a silt loam soil and classified as Inceptisol according to Soil Taxonomy.

The experimental site was previously conventionally tilled for more than 30 years and the basic soil properties were analyzed before the setup of the experimental plots, as shown in Table 1. Since the entire experimental site was homogenous from a soil physical, soil chemical and topographical point of view, the different treatments could be laid out as single plots, which reduces the total size of the experimental site and hence the variability. Statistical analysis of the effects of different soil management practices can therefore be done using replicated samples from single plots.

Within the experimental site, two series of plots were laid out; one series was kept under natural rainfall, whereas the other series was used specially for rainfall simulation tests (see Schiettecatte et al., 2005). In the current study, we will consider the plots which were under natural rainfall conditions only. Per tillage practice, one $30 \mathrm{~m} \times 3 \mathrm{~m}$ plot was established. The slope degree of the plots, which were located along the same contour line and $1 \mathrm{~m}$ apart, was $9 \%$. Each plot was equipped with three 2-m long access tubes for watercontent readings, i.e. at the upslope, midslope and downslope part of the plot, which enabled monitoring soil-water content at selected depths. All plots further contained a set of 8 tensiometers installed in two rows at a inter and intra row distance of $10 \mathrm{~cm}$ at depths of 10 , 20, 30, 40, 50, 70, 90 and $120 \mathrm{~cm}$. One plot was equipped with 4 additional sets of 8 tensiometers to determine possible lateral subsurface flow. At the downslope bottom of each plot, a flume with automatic discharge gauge and a collector drum were installed.

Six replicate cores from each plot were taken randomly for organic carbon (OC) analyses using Walkley and Black (1934) method and for soil bulk density in early of August, 2005 for each plot (Table 2). Changes in frequency and intensity of tillage practices altered the bulk density in the $0-40 \mathrm{~cm}$ layer. NT had the highest bulk density, followed by SS, but the difference was not statistically significant compared to CT. However, the influence of tillage on bulk density in the layer $40-60 \mathrm{~cm}$ was not as pronounced as in the surface layer. The RT, CT and TC had similar bulk density throughout the soil profile. The SS and NT increased soil OC, but again did not reach statistical significance compared to CT. There was no difference of OC between the other treatments. Tillage had negligible effects on the OC in the 30-60 cm soil layer.

During the period 1970-1999, the minimum temperature was $-23.5^{\circ} \mathrm{C}$ and the maximum $43.7^{\circ} \mathrm{C}$. The annual potential evaporation was estimated to vary between 1262 and $1852 \mathrm{~mm}$. The average air humidity was $65 \%$. The annual precipitation in the

Table 2

Bulk density and organic carbon under different soil management practices in $2005(n=6)$

\begin{tabular}{|c|c|c|c|c|c|}
\hline Depth (cm) & RT & NT & $\mathrm{TC}$ & SS & $\mathrm{CT}$ \\
\hline \multicolumn{6}{|c|}{ Bulk density $\left(\mathrm{Mg} \mathrm{m}^{-3}\right)$} \\
\hline $0-20$ & $1.355(0.089)^{\mathrm{a}}$ & $1.531(0.024)$ & $1.358(0.048)$ & $1.467(0.039)$ & $1.359(0.061)$ \\
\hline $20-40$ & $1.364(0.071)$ & $1.503(0.032)$ & $1.369(0.053)$ & $1.445(0.027)$ & $1.367(0.062)$ \\
\hline $40-60$ & $1.467(0.038)$ & $1.472(0.031)$ & $1.483(0.041)$ & $1.489(0.041)$ & $1.494(0.031)$ \\
\hline \multicolumn{6}{|l|}{$\mathrm{OC}\left(\mathrm{g} \mathrm{kg}^{-1}\right)$} \\
\hline $0-10$ & $7.622(1.031)$ & $9.200(0.438)$ & $7.660(0.215)$ & $9.440(0.790)$ & $7.862(0.604)$ \\
\hline $10-20$ & $6.449(0.588)$ & $6.382(0.493)$ & $6.596(0.307)$ & $7.051(0.490)$ & $7.054(0.250)$ \\
\hline $20-30$ & $5.078(1.021)$ & $5.700(0.129)$ & $5.396(0.143)$ & $5.625(0.551)$ & $5.494(0.893)$ \\
\hline $30-60$ & $2.918(0.563)$ & $3.011(0.420)$ & $3.002(0.715)$ & $2.846(0.665)$ & $3.104(0.512)$ \\
\hline
\end{tabular}

\footnotetext{
${ }^{\mathrm{a}}$ Values between brackets indicate standard error.
} 
Table 3

Monthly precipitation, precipitation during fallow period $\left(P_{\mathrm{f}}\right)$, precipitation during growing period $\left(P_{\mathrm{g}}\right)$ and total precipitation during the growing year in Songzhuang (Henan Province)

\begin{tabular}{|c|c|c|c|c|c|c|c|c|c|c|c|c|c|c|c|}
\hline \multirow{2}{*}{$\begin{array}{l}\text { Growing } \\
\text { year }\end{array}$} & \multicolumn{15}{|c|}{ Precipitation $(\mathrm{mm})$} \\
\hline & June & July & August & September & October & November & December & January & February & March & April & May & $P_{\mathrm{f}}$ & $P_{\mathrm{g}}$ & Total \\
\hline $2000-2001$ & 52 & 156 & 215 & 164 & 77 & 23 & 6 & 34 & 18 & 3 & 21 & 6 & 548 & 196 & 744 \\
\hline 2001-2002 & 98 & 239 & 23 & 42 & 52 & 3 & 30 & 6 & 2 & 40 & 37 & 170 & 365 & 364 & 729 \\
\hline $2002-2003$ & 74 & 70 & 56 & 92 & 50 & 1 & 25 & 7 & 22 & 30 & 28 & 66 & 292 & 283 & 575 \\
\hline 2003-2004 & 143 & 236 & 240 & 210 & 123 & 45 & 15 & 2 & 31 & 8 & 11 & 118 & 830 & 306 & 1136 \\
\hline 2004-2005 & 166 & 197 & 109 & 141 & 28 & 23 & 19 & 0 & 5 & 0 & 7 & 29 & 624 & 95 & 719 \\
\hline 1970-1999 & 61 & 133 & 99 & 77 & 41 & 23 & 7 & 6 & 11 & 28 & 39 & 50 & 369 & 205 & 575 \\
\hline
\end{tabular}

area varied from 550 to $864 \mathrm{~mm}$. Rainfall is, however, not evenly distributed throughout the year. High rain intensities and frequent rainstorms typically occur in summer (June-September), whereas in general, the winter months (December-February) are the driest. Table 3 shows the monthly precipitation data from the Menjing County Metrological station which is $5 \mathrm{~km}$ away from the research base during the study period 2000-2005 and the average monthly values during the period 1970-1999. The total precipitation per agricultural year showed a great variability in the Chinese Loess Plateau from 2000 to 2005 . The total precipitation in the 2003-2004 agricultural year was much higher than average and amounted to $1136 \mathrm{~mm}$, which was the highest record over the last 40 years. The lowest total precipitation, $575 \mathrm{~mm}$, was observed in 2002 2003, which however was equal to the average over the period 1970-1999. The distribution of monthly precipitation was also uneven. Monthly precipitation was highest in July 2001 (239 mm), but unexpectedly low in the following months (with $23 \mathrm{~mm}$ in August 2001 and $42 \mathrm{~mm}$ in September 2001).

\subsection{Tillage practices}

Five tillage practices were applied: conventional tillage (CT), no till (NT), reduced tillage (RT), subsoiling (SS) and a two-crop rotation per year (TC). On CT, RT, NT and SS, winter wheat (T. aestivum L.) was monocultivated, whereas on TC, peanut (Arachis hypogaea L.) was grown prior to sowing of winter wheat.

The five practices can be described as follows.

Conventional tillage $(C T)$. Ten to fifteen centimetres long stubble remains on the field after harvest (25 May1 June). Straw and ears are removed from the plot at harvest. In the first week of July, the soil is ploughed and turned to a $20 \mathrm{~cm}$ depth. Around 1 October, just before sowing, the soil is ploughed again and turned to a $20 \mathrm{~cm}$ depth, while at the same time the fertilizer is incorporated, followed by harrowing (seed bed preparation, $5-8 \mathrm{~cm}$ ). Sowing of winter wheat is done around 5 October.

Reduced tillage (RT). Ten to fifteen centimetres long stubble remains on the field after harvest (25 May-1 June). Straw and ears are removed from the plot at harvest. Around 15 July, deep ploughing $(25-30 \mathrm{~cm})$ combined with harrowing $(5-8 \mathrm{~cm})$ is done. Winter wheat is sown around 5 October. This practice thus involves only one ploughing operation instead of two as under CT.

No tillage (NT). Thirty centimetres tall stubble remains on the field after harvest (25 May-1 June) and straw is returned to the field after threshing. Between 25 September and 5 October, direct sowing with fertilizer application is done by hand.

Subsoiling (SS). Twenty-five to thirty-five centimetres tall stubble remains on the field after harvest (25 May-1 June). Around 1 July, subsoiling is performed till $30-35 \mathrm{~cm}$ depth at $60 \mathrm{~cm}$ intervals. Between 25 September and 5 October, direct sowing with fertilizer application is done by hand.

Two-crop rotation (TC). Ten to fifteen centimetres long stubble remains on the field after harvest of winter wheat (25 May-1 June). Peanut is directly sown at the beginning of June and each pit is supplied with a limited amount of water to ensure its germination. No fertilization is applied. After harvest of peanuts (23 September), the soil is ploughed to $20 \mathrm{~cm}$ depth, while at the same time the fertilizer is incorporated, followed by harrowing (seed bed preparation, $5-8 \mathrm{~cm}$ depth). Sowing of winter wheat is done around 5 October.

Yearly fertilizer application rates for each plot were $150 \mathrm{~kg} \mathrm{~N} \mathrm{ha}^{-1}$ and $90 \mathrm{~kg} \mathrm{P}_{2} \mathrm{O}_{5} \mathrm{ha}^{-1}$. Protection against insects (mainly budworm) in the cultivars was applied in the elongation or anthesis stages of winter wheat by applying $1125 \mathrm{ml}$ omethoate $\left(\mathrm{C}_{5} \mathrm{H}_{12} \mathrm{NO}_{4} \mathrm{PS}\right) \mathrm{ha}^{-1}$ at a concentration of $35 \mu \mathrm{g} \mathrm{L}^{-1}$. 


\subsection{Soil water balance}

The water balance in the rootzone over a given period $\Delta t$ is given by

$\Delta S=P+I-\mathrm{ET}-R-D+L_{\mathrm{i}}-L_{\mathrm{o}}$

where $\Delta S$ is the change in soil-water storage in the rootzone (i.e. between the soil surface and maximum rooting depth), $P$ the precipitation, $I$ the applied irrigation water, ET the evapotranspiration (or evaporation in case of a bare soil), $R$ the surface runoff, $D$ the capillary rise (if negative) or drainage (if positive) at the maximum rooting depth, and $L_{\mathrm{i}}$ and $L_{\mathrm{o}}$ are the lateral inflow and outflow, respectively. All components are expressed in units of length $(\mathrm{mm})$.

There is no irrigation in the dryland of the Loess Plateau. However, on the TC plot, each pit was supplied with a limited amount of water to ensure germination of peanuts. To determine lateral inflow and outflow, one plot (the CT plot) was equipped with five sets of tensiometers installed at downslope intervals of $5 \mathrm{~m}$. The computed equipotential lines on CT plot and on the rainfall simulation plots showed, however, that $L_{\mathrm{i}}$ and $L_{\mathrm{o}}$ were negligibly small during the complete measuring campaign.

Changes in soil-water storage were quantified from soil-water content profiles which were obtained using a Trime $^{\circledR}$ Tube Probe (Imko, Germany) which is a modified TDR probe especially designed for water content profiling. It was calibrated both in the laboratory and on the field prior to the water balance experiment. Soil-water content was recorded at regular times at depths of 10, 20, 30, 40, 50, 70, 90, 120 and $160 \mathrm{~cm}$. The tube probe consists of a cylindrical PVC body which has four spring-mounted aluminium plates as TDR wave guides on opposite sides. The two plates on each side have a total length of $18 \mathrm{~cm}$, which corresponds to the length of the sphere of influence of the probe. Experiments in a loamy sand (with clay content of $5.7 \%$, silt content of $8.3 \%$, sand content of $86.0 \%$, organic carbon content of $2.0 \%$ and a bulk density of $1.5 \mathrm{Mg} \mathrm{m}^{-3}$ ) have shown that the diameter of the sphere of influence is 11 to $15 \mathrm{~cm}$ depending on the water content. It was further shown that the influence of temperature was negligible. Per depth and access tube, water content was measured in three replicates by rotating the tube probe over an angle of $60^{\circ}$. Since per plot, three access tubes were installed, nine water content values were recorded per depth and time, and the arithmetic mean was taken.

Precipitation was measured by a tipping-bucket rain gauge connected to a nearby weather station. Runoff was monitored automatically using RBC flumes with pressure transducers connected to a datalogger (Eijkelkamp Agrisearch Equipment, Giesbeek, The Netherlands). Total runoff was also determined from the total volume of water collected in the drums after each rain event. Drainage and capillary rise were determined at a depth of $105 \mathrm{~cm}$ from tensiometer readings and soilwater content measurements at 90 and $120 \mathrm{~cm}$ using the Buckingham-Darcy equation:

$D=q \Delta t=-K(\bar{\theta}) \frac{\mathrm{d} \bar{H}}{\mathrm{~d} z} \Delta t$

where $K(\theta)$ is the hydraulic conductivity corresponding to the (volumetric) soil water content $\theta, \mathrm{d} H / \mathrm{d} z$ the hydraulic-head gradient, and the overbars denote time-averaged values. The hydraulic conductivity was computed using the Mualem-van Genuchten equation (Mualem, 1976; Van Genuchten, 1980). Saturated hydraulic conductivity was measured in the field with a tension infiltrometer (Soil Measurement Systems, Tuczon, AR, USA) using Wooding's equation in combination with Gardner's equation. The Van Genuchten (1980) parameters were obtained by non-linear regression to water retention data. Soilwater retention curves were determined on $100-\mathrm{cm}^{3}$ undisturbed soil cores using tension tables (Eijkelkamp Agrisearch Equipment, Giesbeek, The Netherlands) and pressure chambers (Soilmoisture Equipment, Santa Barbara, CA, USA). The computed hydraulic conductivity values were cross-checked with hydraulic conductivity data obtained from the plane-of-zero-flux method (Maesschalck et al., 1984), which allows calculating the drainage component $D$ as the difference in soil-water storage between the plane of zero flux (if present) and a given depth below for those cases in which the actual rooting depth does not exceed the plane of zero flux. The presence of a zero flux plane could be deduced from monitoring hydraulic potential with tensiometers installed at depths of $10,20,30,40,50,70,90$, and $120 \mathrm{~cm}$. All tensiometers were connected to mercury manometers which were shaded against direct sunlight. The results shown by Cornelis et al. (2004) indicated that at the experimental site the drainage component at $105 \mathrm{~cm}$ was negligible. Therefore, the soil-water balance equation could be simplified as

$\Delta S=P-\mathrm{ET}-R$

where soil-water storage $S$ was calculated between the soil surface and a depth of $160 \mathrm{~cm}$ using the trapeze rule, allowing to compute the evolution of evapotranspiration with time for the different treatments. 


\subsection{Efficiency of soil management practice in terms of water conservation}

The soil management regime affects both the storage of precipitation water and its use by the crops. Since precipitation is the sole water supply in the rainfed area of the Loess Plateau, we expressed the efficiency of the soil management practice in terms of precipitation storage efficiency (PSE) and precipitation use efficiency (PUE). PSE (Leng and Han, 1996; Tanaka and Anderson, 1997) was calculated as the change in soil water storage within the $0-160 \mathrm{~cm}$ depth soil profile during the fallow period divided by precipitation during the fallow period. Note that in case of the two-crop system, the 'fallow' period coincides with the peanut growing period.

PUE (Le Houerou, 1984) was determined as the ratio of crop production (grain yield, $\mathrm{kg} \mathrm{ha}^{-1}$ ) to effective precipitation $(\mathrm{mm})$ during the whole crop growing season (including the fallow period and the winter wheat growing period), or yield ( $\mathrm{kg}$ ) per cubic metre of effective precipitation. Effective precipitation is the amount of rainfall that can be used by the plant and equals total precipitation $P$ less runoff $R$ (Maesschalck et al., 1984). For each plot, yield was determined in three replicates, and is the dry mass of nuts and seeds of peanut and winter wheat, respectively, harvested from $1.2 \mathrm{~m} \times 3 \mathrm{~m}$ large subplots.

\section{Results}

\subsection{Rainfall distribution}

Table 3 shows for the five agricultural years (i.e. from 1 June till 31 May) under study the precipitation during the growing period of winter wheat, $P_{\mathrm{g}}(\mathrm{mm})$, i.e. from sowing time around 1 October to harvest time around 1 June of the next year, as well as during the fallow period, $P_{\mathrm{f}}(\mathrm{mm})$, which corresponds to the rest of the agricultural year. As can be observed, both $P_{\mathrm{g}}$ and $P_{\mathrm{f}}$ showed a large variation. For instance, $P_{\mathrm{f}}$ of 2002-2003 was very low $(292 \mathrm{~mm})$ compared to the exceptional high values of $P_{\mathrm{f}}$ in the consecutive year $(830 \mathrm{~mm}) . P_{\mathrm{f}}$ was lower than average (for the period 1970-1999) in 2002-2003 only. On the other hand, $P_{\mathrm{g}}$ of 2001-2002 was more than three times (364 mm) that of 2004-2005

Table 4

Components of the soil-water balance for the different tillage practices for the five agricultural years under study $(n=3)$

\begin{tabular}{|c|c|c|c|c|c|c|c|c|c|c|}
\hline \multirow[t]{2}{*}{ Agricultural year } & \multirow[t]{2}{*}{ Tillage practice } & \multirow[t]{2}{*}{$S_{\mathrm{i}}(\mathrm{mm})$} & \multirow[t]{2}{*}{$S_{\mathrm{o}}(\mathrm{mm})$} & \multirow[t]{2}{*}{$S_{\mathrm{e}}(\mathrm{mm})$} & \multicolumn{3}{|c|}{ Fallow period } & \multicolumn{3}{|c|}{ Growing period } \\
\hline & & & & & $\Delta S(\mathrm{~mm})$ & $R(\mathrm{~mm})$ & $\mathrm{ET}(\mathrm{mm})$ & $\Delta S(\mathrm{~mm})$ & $R(\mathrm{~mm})$ & $\mathrm{ET}(\mathrm{mm})$ \\
\hline \multirow[t]{5}{*}{ 2000-2001 } & RT & 262 & 314 & 241 & 52 & 7 & 429 & -72 & 0 & 328 \\
\hline & NT & 268 & 415 & 245 & 147 & 4 & 382 & -170 & 0 & 380 \\
\hline & $\mathrm{TC}$ & 264 & 320 & 254 & 56 & 4 & 479 & -66 & 0 & 270 \\
\hline & SS & 262 & 415 & 251 & 153 & 5 & 384 & -164 & 0 & 366 \\
\hline & $\mathrm{CT}$ & 262 & 378 & 240 & 126 & 8 & 384 & -139 & 0 & 364 \\
\hline \multirow[t]{5}{*}{ 2001-2002 } & $\mathrm{RT}$ & 241 & 317 & 291 & 76 & 4 & 336 & -26 & 0 & 341 \\
\hline & NT & 245 & 398 & 292 & 152 & 1 & 276 & -106 & 0 & 407 \\
\hline & $\mathrm{TC}$ & 254 & 276 & 283 & 22 & 3 & 388 & 7 & 0 & 311 \\
\hline & SS & 251 & 394 & 279 & 143 & 1 & 278 & -115 & 0 & 423 \\
\hline & $\mathrm{CT}$ & 240 & 362 & 276 & 123 & 6 & 283 & -86 & 0 & 405 \\
\hline \multirow[t]{5}{*}{ 2002-2003 } & RT & 291 & 312 & 279 & 21 & 0 & 271 & -32 & 0 & 316 \\
\hline & NT & 292 & 352 & 295 & 60 & 0 & 232 & -57 & 0 & 341 \\
\hline & $\mathrm{TC}$ & 283 & 282 & 273 & 0 & 0 & 292 & -9 & 0 & 293 \\
\hline & SS & 279 & 337 & 284 & 58 & 0 & 234 & -53 & 0 & 337 \\
\hline & $\mathrm{CT}$ & 276 & 312 & 271 & 36 & 0 & 256 & -41 & 0 & 324 \\
\hline \multirow[t]{5}{*}{ 2003-2004 } & RT & 279 & 547 & 294 & 268 & 11 & 551 & -253 & 0 & 559 \\
\hline & NT & 295 & 575 & 310 & 281 & 2 & 547 & -266 & 0 & 572 \\
\hline & $\mathrm{TC}$ & 273 & 576 & 303 & 303 & 3 & 524 & -274 & 0 & 580 \\
\hline & SS & 284 & 574 & 297 & 291 & 1 & 539 & -277 & 0 & 584 \\
\hline & $\mathrm{CT}$ & 271 & 572 & 289 & 301 & 14 & 515 & -282 & 0 & 589 \\
\hline \multirow[t]{5}{*}{ 2004-2005 } & RT & 294 & 446 & 233 & 152 & 17 & 455 & -214 & 0 & 309 \\
\hline & NT & 310 & 485 & 236 & 175 & 2 & 447 & -249 & 0 & 344 \\
\hline & $\mathrm{TC}$ & 303 & 418 & 247 & 116 & 13 & 495 & -171 & 0 & 266 \\
\hline & SS & 297 & 482 & 243 & 185 & 2 & 437 & -239 & 0 & 334 \\
\hline & $\mathrm{CT}$ & 289 & 433 & 235 & 143 & 16 & 465 & -198 & 0 & 293 \\
\hline
\end{tabular}


(95 mm) which suffered from a long dry spell lasting from January to the end of May. The years 2000-2001 and 2004-2005 had a $P_{\mathrm{g}}$ lower than average.

\subsection{Runoff, change in soil-water storage and evapotranspiration}

The different components of the field soil-water balance for the five soil management practices within the five agricultural years under study are given in Table 4. The results indicate that NT and SS had a beneficial effect on runoff reduction from the second year on. Application of RT had a negative impact on runoff reduction compared to conventional tillage.
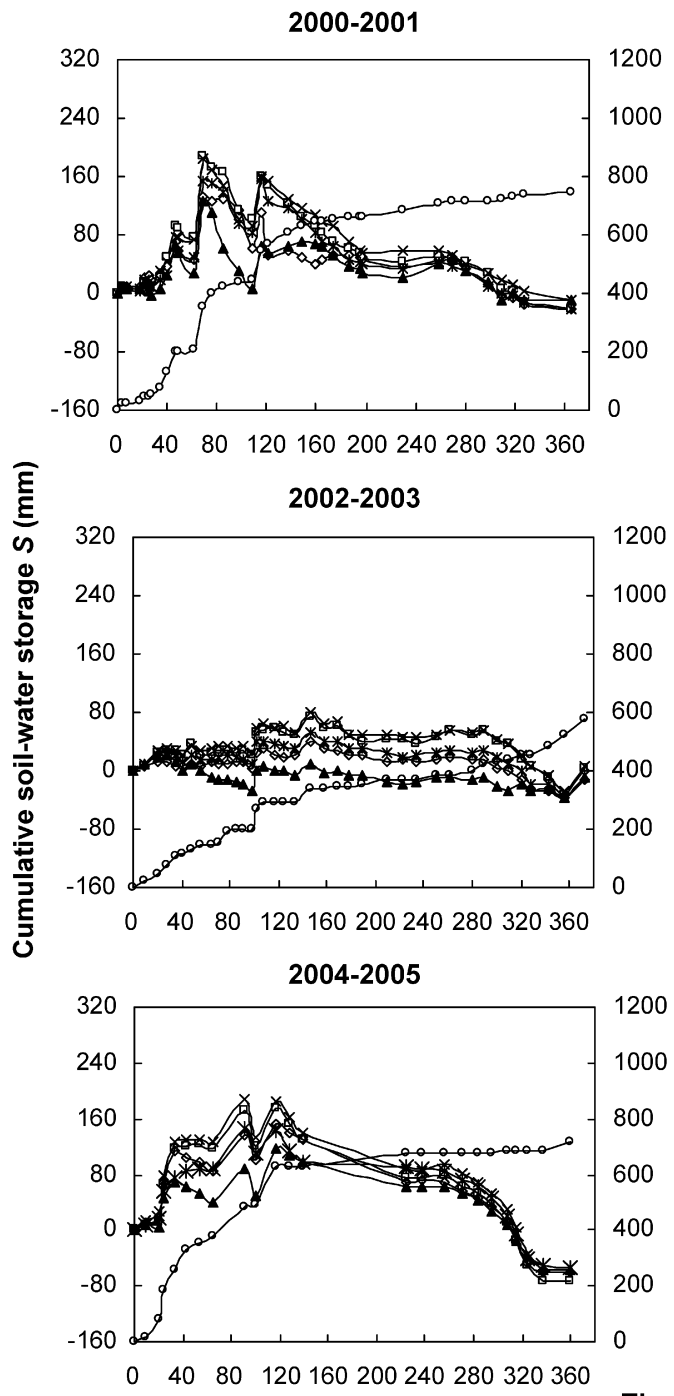

Time (days)
Fig. 1 shows for the five tillage practices the cumulative change in soil-water storage over a depth of $160 \mathrm{~cm}$ as a function of time for the five agricultural years under study. The water storage is expressed as cumulative water storage which was set to zero on the first day of each growing year). Since each plot received the same amount of precipitation, the evolution in cumulative $S$ reflects the difference in $R$ and ET. In general, conservation tillage practices (NT and SS) have a noticeable effect on $S$, but much less than did variations in $P$. At the end of the fallow period of each growing seasonthe fallow period lasts from day 1 to around day 125-the highest cumulative $S$ was observed in NT and SS, followed by CT, except in years 2003-2004, in which TC
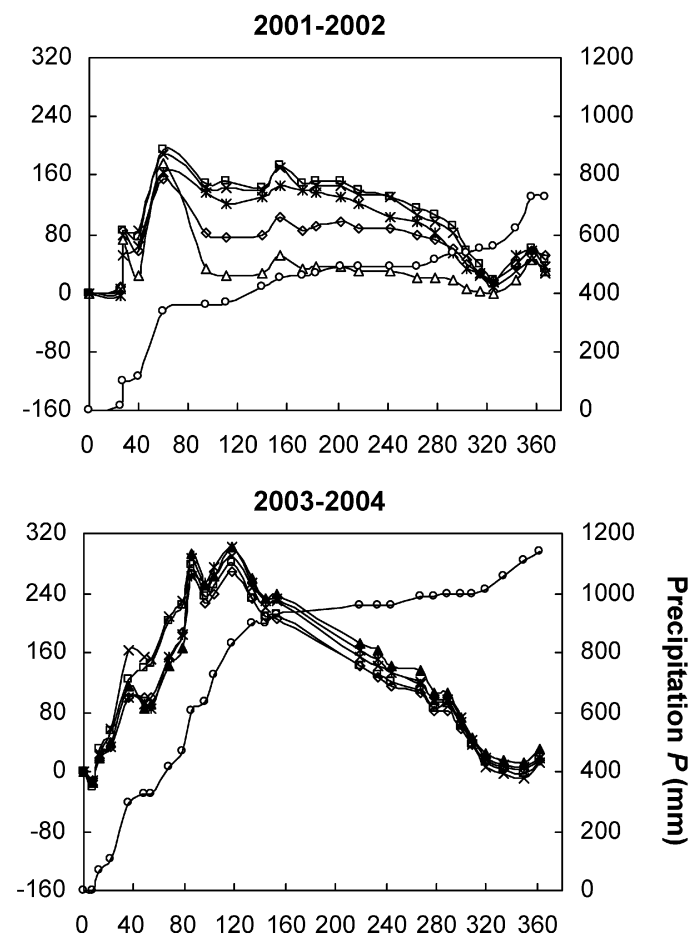

Fig. 1. Evolution of cumulative soil-water storage $S$ with time for the different tillage practices for the five agricultural years under study. Day 1 corresponds to 1 June, which is the first day of the fallow period (and of the winter wheat growing season). Winter wheat is sown at around 3 October day 125 , except in year 2003-2004, in which winter wheat sowing was postponed with 20 days. 
and CT showed the highest cumulative $S$ (respectively, 303 and $301 \mathrm{~mm}$ ) (see also Table 3). This can be explained by the exceptional high precipitation during the fallow period $P_{\mathrm{f}}$ of 2003-2004. Whereas $S$ was still highest in SS and NT around day 40, it became highest in TC and CT towards the end of the fallow period. This is due to ploughing before seeding winter wheat in case of TC and CT, which improved the infiltration of the rainwater. At the end of the fallow period, unexpected consecutive rainy days with low rainfall intensities were observed, which also reduced the risk of runoff. In general, the RT practice showed a somewhat lower cumulative $S$ compared to CT due to the soil surface being bare during the fallow time. The lowest cumulative $S$ in the TC rotation for all years except 2003-2004, was due to the extra water consumption by peanut ().

During the growing period of winter wheat (from around day 125 to 365), a reversed picture was found. Higher reductions in $S$ were observed for the conservation tillage practices NT and SS compared to CT, except in 2003-2004, in which CT showed the highest $S$ reduction $(-282 \mathrm{~mm})$. In all years, $S$ at the end of the growing season $\left(S_{\mathrm{e}}\right)$ was similar irrespective of the adapted tillage practice and rotation system. The difference in $S$ at the end of the growing period between the treatments ranged from $13 \mathrm{~mm}$ in $2000-2001$ to $24 \mathrm{~mm}$ in 2002-2003. However, the variation in $S$ at the end of the growing period among different years was high. This can be mainly attributed to the precipitation in the late winter wheat season stage, which was exceptionally low in 2004-2005 and high in 20032004. The difference between $S$ at the beginning of the winter wheat growing season (day 125) and $S$ at the beginning of the fallow time (day 1) ranged from $0 \mathrm{~mm}$ for CT in 2002-2003 to $303 \mathrm{~mm}$ for SS in 2003-2004. For all treatments the highest $S$ reductions were observed in 2004-2005. This was due to the extremely low precipitation during the growing period $\left(P_{\mathrm{g}}=95 \mathrm{~mm}\right)$, with $\Delta S$ for the complete winter wheat growing season (days $0-365$ ) ranging from $-55 \mathrm{~mm}$ for TC to $-74 \mathrm{~mm}$ for NT. The lowest cumulative reduction in water storage at the end of growing season was observed for all tillage practices in 2001-2002, ranging between $-28 \mathrm{~mm}$ for SS and $-50 \mathrm{~mm}$ for RT. This can be mainly explained by the high precipitation during the 2001-2002 growing period (364 mm). Conventional tillage resulted in all years in an intermediate cumulative reduction in $S$ during the growing period of winter wheat. The total soil-water storage during its fallow period was $13.8 \%$ greater with SS and $11.7 \%$ greater with NT treatment than with CT. In all but the years with a relative wet fallow period, i.e.
2003-2004 and 2004-2005, RT was much less efficient in storing water compared to CT.

The evolution of cumulative evapotranspiration with time is plotted in Fig. 2. At the end of the fallow period, the loss of water by evaporation was lowest in SS and NT, followed by CT and RT, except in 2003-2004 which had an exceptional wet fallow period. Due to transpiration of peanuts, ET in TC was for all but the years 2003-2004 highest. For all practices, larger variations were observed between the years. Total ET during the fallow period ranged from $232 \mathrm{~mm}$ for SS in 2002-2003 to $551 \mathrm{~mm}$ for RT in 2003-2004, or when calculated on a daily basis, ET rates varied between, respectively, 1.7 and $4.4 \mathrm{~mm} \mathrm{day}^{-1}$. Due to the exceptional high rains in 2003-2004, those rates could be close to potential because of probably optimal soil water conditions.

When considering ET during the winter wheat growing period, highest increases (steepest curves), indicating highest root water uptake and hence crop activity, were observed for SS and NT, followed by CT, except again for 2003-2004. This was most manifest in 2002-2003 which received the lowest amounts of rainfall during the fallow period. Also here, yearly variations are most apparent, varying from around $571 \mathrm{~mm}$ for SS and NT in 2002-2003 to $1122 \mathrm{~mm}$ for SS in 2003-2004, or in ET rates between, respectively, 1.6 and $3.1 \mathrm{~mm} \mathrm{day}^{-1}$.

\subsection{Effect of tillage on water conservation and precipitation use efficiency}

The effectiveness of the tillage practices in storing rainwater relative to the amount of rainfall during the fallow period, expressed in terms of PSE, in yield and use of effective rainfall, expressed as PUE, is summarised in Table 5 for the five agricultural years under study. Tillage practices significantly influenced PSE. It was greatest for SS and NT, followed by CT, except in 2003-2004 in which precipitation was extremely high $(830 \mathrm{~mm})$. In 2004-2005, which also had a wet fallow period $(624 \mathrm{~mm})$, the differences between NT and CT were minimal, but SS showed a somewhat higher PSE value. The differences between SS and NT on the one hand, and CT on the other were most pronounced in 2001-2002 and 2002-2003, which suffered from a relatively dry fallow period with only $365 \mathrm{~mm}$ and $292 \mathrm{~mm}$ of rain. Overall, less than $42 \%$ of $P_{\mathrm{f}}$ was stored in the soil. Given the relatively low runoff amounts, this means that more than $58 \%$ of $P_{\mathrm{f}}$ was lost by evaporation.

In general, winter wheat yields were highest with SS, except in 2004-2005 were SS was second best. CT 
2000-2001

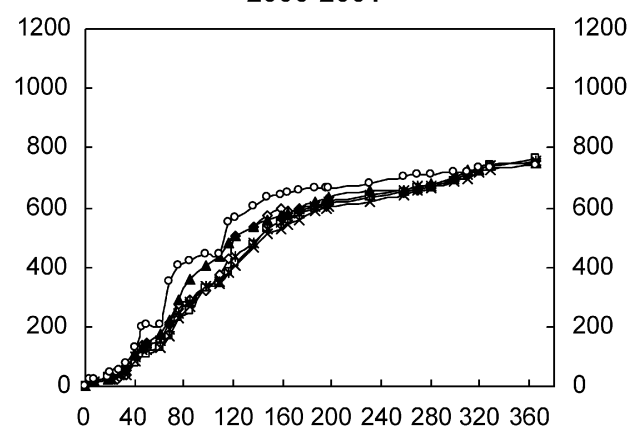

2002-2003

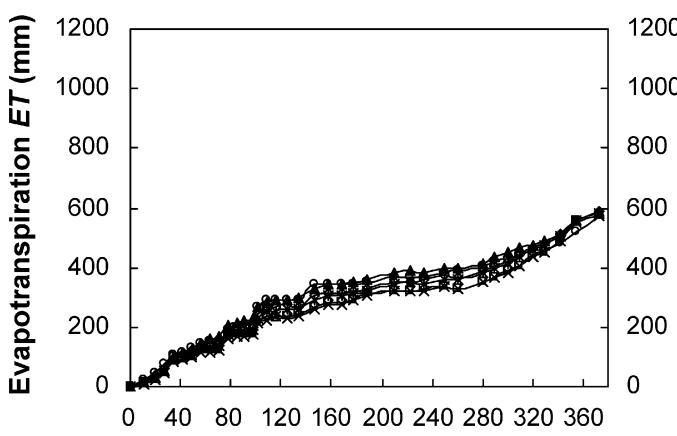

2004-2005

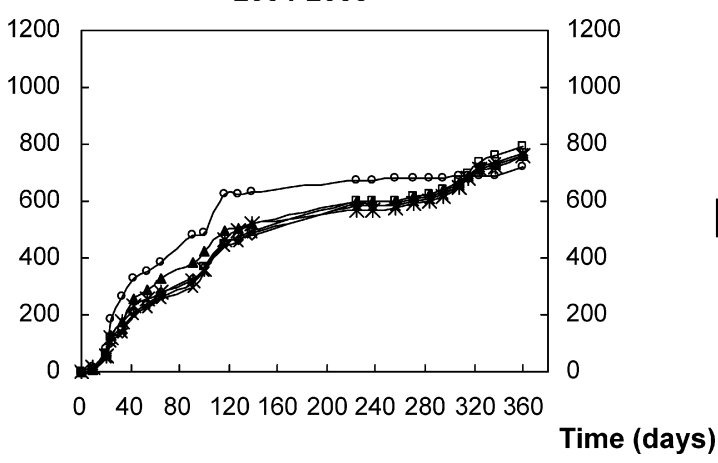

2001-2002

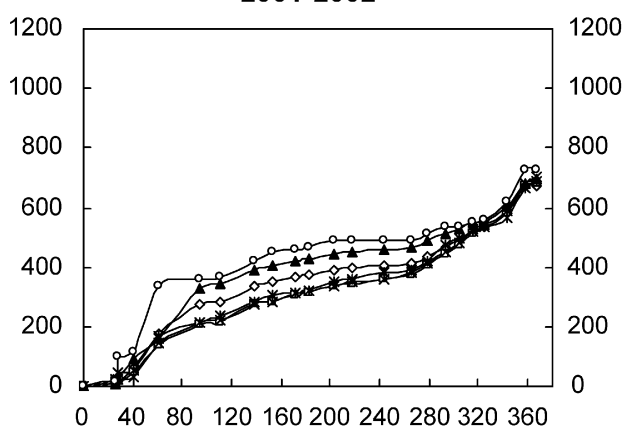

2003-2004

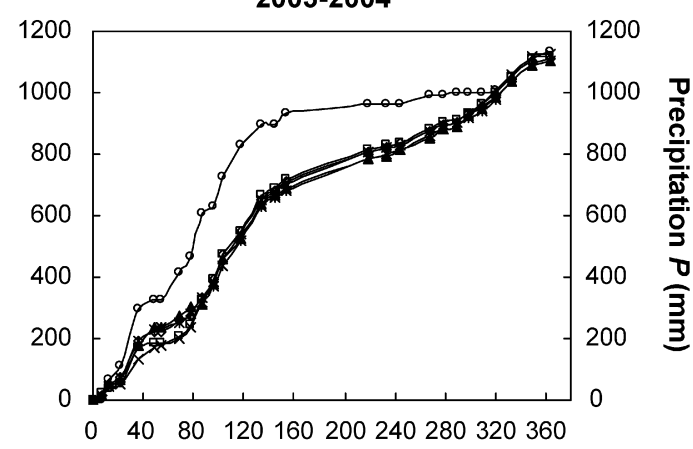

Fig. 2. Same as Fig. 1, but with ET as a function of time.

showed the second highest winter wheat yield in 20012002 and 2003-2004. In 2000-2001 and 2002-2003, NT resulted in the second highest wheat yields. Significant differences in winter wheat yield between CT on the hand and SS or NT on the other hand were, however, only observed in 2000-2001 and 2002-2003. The agricultural years 2000-2001 had a 'rich' fallow period in terms of precipitation $\left(P_{\mathrm{f}}=624 \mathrm{~mm}\right)$, but a relatively dry winter wheat growing period $\left(P_{\mathrm{g}}=177 \mathrm{~mm}\right)$, whereas 2002-2003 had a relatively dry fallow period $\left(P_{\mathrm{f}}=292 \mathrm{~mm}\right)$, followed by a 'normal' winter wheat growing period $\left(P_{\mathrm{g}}=284 \mathrm{~mm}\right)$. Yield of winter wheat with RT was lower than with CT in 2001-2002, 2003-2004 and 2004-2005, although never significant. The rotation of winter wheat with peanut, TC, resulted in lowest winter wheat yields for all the years. This was mainly attributed to the much higher rootzone depletion at the beginning of the winter wheat growing period because of peanut water consumption. However, when considering the total yields of both crops, the TC system resulted in highest values, except in 20012002 and 2002-2003. Both years experienced a relatively dry 'fallow' period, which in case of TC coincided with the growing period of peanut. In 2001-2002 and 20022003 , the yield of winter wheat was only, respectively, 68.2 and $54.9 \%$ of the winter wheat yield with SS. In the three other years, winter wheat yield of TC ranged from 79.4 to $89.7 \%$ compared to that of SS. 
Table 5

PSE, yield and PUE for the different tillage practices for the five agricultural years under study

\begin{tabular}{|c|c|c|c|c|}
\hline Agricultural year & Tillage practice & PSE $(\%)$ & Yield $\left(\mathrm{kg} \mathrm{ha}^{-1}\right)$ & PUE $\left(\mathrm{kg} \mathrm{m}^{-3}\right)$ \\
\hline \multirow[t]{7}{*}{ 2000-2001 } & $\mathrm{RT}$ & 9.5 & 4047 bc (129) & 0.54 \\
\hline & NT & 26.8 & $4107 \mathrm{bc}(62)$ & 0.54 \\
\hline & $\mathrm{TC}$ & 10.2 & $1191(84)$ & \\
\hline & & & 3662 a (53) & 0.49 \\
\hline & & & $4853 \times(127)$ & 0.65 \\
\hline & SS & 27.9 & 4246 c (142) & 0.57 \\
\hline & CT & 23.0 & $3922 \mathrm{ab}(116)$ & 0.53 \\
\hline \multirow[t]{7}{*}{ 2001-2002 } & $\mathrm{RT}$ & 20.8 & $4473 \mathrm{~b}(235)$ & 0.62 \\
\hline & NT & 41.6 & 4897 bc (233) & 0.67 \\
\hline & $\mathrm{TC}$ & 6.0 & $1044(102)$ & \\
\hline & & & 3737 a (473) & 0.51 \\
\hline & & & $4781 \times(575)$ & 0.66 \\
\hline & SS & 39.2 & 5478 c (366) & 0.75 \\
\hline & $\mathrm{CT}$ & 33.7 & 5169 bc (472) & 0.71 \\
\hline \multirow[t]{7}{*}{ 2002-2003 } & RT & 7.2 & 4347 bc (312) & 0.75 \\
\hline & NT & 20.5 & 4778 cd (168) & 0.83 \\
\hline & $\mathrm{TC}$ & 0 & $1414(222)$ & \\
\hline & & & 2667 a (73) & 0.46 \\
\hline & & & $4081 \times(295)$ & 0.71 \\
\hline & SS & 19.9 & $4857 \mathrm{~d}(88)$ & 0.84 \\
\hline & CT & 12.3 & 4019 b (142) & 0.70 \\
\hline \multirow[t]{7}{*}{ 2003-2004 } & RT & 32.3 & $4109 \mathrm{ab}(100)$ & 0.36 \\
\hline & NT & 33.9 & $4270 \mathrm{ab}(190)$ & 0.38 \\
\hline & $\mathrm{TC}$ & 36.5 & $2197(163)$ & \\
\hline & & & 4088 a (46) & 0.36 \\
\hline & & & $6285 \times(209)$ & 0.55 \\
\hline & SS & 35.1 & 4559 b (268) & 0.40 \\
\hline & CT & 36.3 & $4347 \mathrm{ab}(145)$ & 0.38 \\
\hline \multirow[t]{7}{*}{ 2004-2005 } & RT & 24.4 & $4574 \mathrm{ab}(215)$ & 0.64 \\
\hline & NT & 28.0 & 5292 c (243) & 0.74 \\
\hline & $\mathrm{TC}$ & 18.6 & $1228(159)$ & \\
\hline & & & 4167 a (327) & 0.58 \\
\hline & & & $5395 \times(486)$ & 0.75 \\
\hline & SS & 29.6 & 5245 c (164) & 0.73 \\
\hline & $\mathrm{CT}$ & 22.7 & 4801 bc (77) & 0.67 \\
\hline
\end{tabular}

Values between brackets indicate standard error. Average values in the same column followed by the same letter are not significantly different according to Student-Newman-Keuls test $(\alpha=0.05)$; in case of TC, the first line corresponds to peanut yield and the second to winter wheat yield. Values in italics indicate total yield, being the sum of peanut yield and winter wheat yield. In case of TC the values in italics are based on total yield of winter wheat and peanuts. The other values refer to winter wheat yield only.

When comparing the different years, highest winter wheat yields were observed in 2001-2002 and in 20042005. Both received relatively high amounts of precipitation during the fallow period (respectively, 548 and $624 \mathrm{~mm}$ ), and low amounts in the winter wheat growing period (respectively, 196 and $95 \mathrm{~mm}$ ). It is remarkable that the winter wheat yields in 2003-2004, with its abundant rain in the fallow period, were rather low. Because of the almost saturated water conditions at the end of the fallow period, the sowing time of winter wheat had to be postponed to 28 October, which was 20 days later than normal. The effect of time of sowing on yield has been recognized by Wang (1994) who found that for each ten days delay in sowing, grain yield was reduced by $150-200 \mathrm{~kg} \mathrm{ha}^{-1}$. In addition, soil crusting caused by the heavy rain immediately after sowing severely affected the germination of winter wheat.

With respect to the efficiency in which the effective precipitation was used (PUE), a similar trend as for the winter wheat yield was observed. SS showed highest values, except in the wet 2003-2004, in which NT was best. The differences with $\mathrm{CT}$ were significant in all years except 2001-2002 and 2003-2004, which both showed high $P$ during the winter wheat growing period. The differences between CT and RT were not significant. Again, TC showed the lowest results for 
all years when considering winter wheat yield alone. When, however, accounting for the total yield, including that of peanut, highest values were found for TC except for 2001-2002 and 2002-2003, with their dry 'fallow' period. Overall, PUE was by far lowest in the wettest years 2003-2004, and highest in the driest years 2002-2003.

\section{Discussion}

There is evidence that in the eastern part of the Loess Plateau, a wheat crop needs about $480 \mathrm{~mm}$ of water for maximum yield (Wang, 1994). Although the mean annual precipitation is around $580 \mathrm{~mm}$ in the Chinese Loess Plateau and exceeds this value, it is mainly concentrated in July, August and September, while the average precipitation in the growing period of winter wheat is $205 \mathrm{~mm}$ only. Since the low and variable precipitation during the winter wheat growing period considerably limits rainfed crop yields, increasing water storage within the soil profile is crucial to increase plant available water.

However, due to the combination of low relative humidity, high temperatures, and an uneven distribution of precipitation during the rainy season, soils in the Loess Plateau are generally not filled to field capacity during the fallow period. This was also not the case during our study period, in which matric potentials remained always lower than $-34 \mathrm{kPa}$. More than $60 \%$ of the precipitation during the fallow period was lost through evaporation, which indicates the importance of storing water at sowing to supplement the precipitation during the winter wheat growing period for increasing crop production.

Even though the effect of tillage practices on water storage was much lower than did precipitation variations, small influences of the applied tillage practice on water conservation during the fallow period could greatly affect winter wheat yield. Lafond et al. (1996) demonstrated that the improvement in grain yield with conservation practices is directly related to the additional amount of water that is conserved by the tillage practice. The purpose of ploughing the soil in the CT and RT by local farmers after harvesting winter wheat, i.e. in the early stage of the rainy season, is to increase the retention of rainwater. Although it can result in an increased infiltration of water, it will enhance the loss of water by evaporation compared with a residue-covered surface or an undisturbed soil. Since in the CT and RT practice, the soil is also left bare, it further results in higher runoff.
The conservation tillage practices SS and NT had a noticeable effect on postharvest water storage during the fallow period, except during the wettest years. We found that SS was the best practice in terms of water conservation, crop production and effective use of rain water. It resulted in the highest increase in water storage during the fallow period, highest winter wheat yields and highest PUE. Compared with CT, SS resulted, over the 5 years under study, in a PSE, yield and PUE which were, respectively, 16.6, 9.6 and 10.1\% higher. This can be explained by the standing stubble and residue mulching (Huang et al., 2005). It not only intercepts significant amounts of precipitation, but also reduces runoff by slowing down the water flowing over the surface by overland flow and protects the soil from direct raindrop impact. It further protects the surface from direct radiation and reduces windspeed, hence reducing evaporation from the soil surface (Hillel, 1998). SS is thus effective to more efficiently save precipitation for crop production. Other field studies in the Loess Plateau also demonstrated that SS had a higher water content during both the wheat growing season and the fallow period, and showed higher yields of winter wheat compared to CT (Liang et al., 2002; Wang et al., 2003). This is also in agreement with results found in diverse regions, including Victoria Australia (Cantero-Martinez et al., 1999), Nebraska USA (Lyon et al., 1998), Texas USA (Baumhardt and Jones, 2002), the northern Great Plain in USA (Lenssen et al., 2007) and on a semi-arid Kenya (Gicheru et al., 2004).

Although slightly less effective than SS, NT also had a pronounced effect on conservation of water. Over the 5 years under study, its PSE, yield and PUE was, respectively, 12.0, 4.9 and 5.8\% larger than for CT. Our results on yield under NT are in agreement with Halvorson et al. (2000) who reported differences in wheat yield between CT and NT in specific conditions: in dry years NT was more productive than CT, whilst the reverse was true when rainfall was greater. Even though NT had a comparable effect as SS on water conservation, its yield response was not as clear as SS except in the last year. The somewhat better results that were observed with SS can be attributed to a slightly better infiltration after subsoiling and the breaking up of the continuity of flow paths in the soil (Hillel, 1998). The soil compaction in NT adversely affects soil properties, resulting in a relatively lower PUE compared to SS (Lipiec and Hatano, 2003). However, NT had the highest yield in the last year which could be accounted for by the improved soil physical and chemical conditions after 6 years of consecutive NT practice. According to Franzluebbers (2002), sufficient biological activity will be established, a stable soil 
structure will be formed and water infiltration will increase in soils for many years of continuous NT practices. This conclusion was corroborated by the research of Fabrizzi et al. (2005), who found that after 5 years of continuous NT practices, bulk density tended to stabilize. The observed compaction only lasts for a few years. As a consequence, we could expect that continuous NT practice would result in a higher yield response in the coming years.

On the other hand, RT resulted overall in lower PSE, yield and PUE values, being, respectively, 27.4, 3.2 and $2.3 \%$ lower than CT. Deep ploughing the soil and harrowing it at around day 45 seemed to increase evaporation in the drier years (Fig. 2), compared to rather superficially ploughing without harrowing at around day 30 as in CT. It also resulted in higher runoff values during the wetter years, which could be attributed to a lower aggregate stability due to harrowing.

One of the main purposes of fallowing in the Loess Plateau is to increase the storage of water for a subsequent crop. However, no matter which kind of tillage practices was adapted, PSE never exceeded $42 \%$, the rest being slightly lost by runoff, but primarily by evaporation. This indicates that traditional fallow farming utilizes precipitation water inefficient. Cropping systems should be adjusted to precipitation patterns for better soil water use. More intensive cropping with fewer fallow appears to be possible on the drylands of the Loess Plateau. The adoption of peanuts e.g. provides a continuum of crop growth, from the commencement of the rainy season until most of the available moisture is depleted due to crop transpiration. The additional yield of peanut offers a considerable additional income to the local farmer. Our results show that farmers in the Chinese Loess Plateau can optionally include peanut in an annual dryland cropping rotation, in particular when a relatively wet fallow period is predicted. In case of drier fallow periods, we found lower total yields of winter wheat and peanut, compared to the SS and NT. Furthermore, the frequently prevailing drought stress at the sowing time of peanut can severely affect peanut germination and plant establishment, and may cause serious reductions in peanut growth and yield. In order to assure the seed germination, limited water was supplied in our study for TC. As compared to CT, yield and PUE of winter wheat was 17.7 and $19.6 \%$ lower for TC. However, when considering the total yield of both winter wheat and peanut, yield and PUE with TC were, respectively, 14.1 and $10.9 \%$ higher than with CT. PSE with TC was $44.1 \%$ lower than with CT, since a large part of the rainwater was taken up by peanut.
The effects of NT and SS practices were most pronounced during the drier years, although even then, the differences with conventional tillage are not that substantial. However, from a broader and economic viewpoint, conservation tillage has the additional advantage that it needs fewer farming operations, hence reducing the total cost of crop production. It will further reduce the risk on crop failure for years drier than those under study. For other benefits of conservation tillage compared to conventional tillage, the reader is referred to, e.g. Holland (2004).

\section{Conclusions}

Water is the most limiting factor for crop production in dryland farming in the Chinese Loess Plateau. This study showed that, from a waterconserving perspective, conservation tillage (SS and NT) could be an ecologically sound approach in the drylands of the Loess Plateau. SS practices significantly increased the precipitation storage efficiency and the water use efficiency. Over our study period (2000-2005) SS was the most suitable conservation tillage. Although in general, NT had a less pronounced positive effect on yield, 6 years consecutive NT practice resulted in the highest yield in the last year, which may be an indication that in the longer term, it may be as good an alternative as SS. The two crops system decreased the yield of winter wheat; however, it still showed promising results considering the economic income and the efficient use of rain water. CT gave intermediate results, whereas RT was the worst alternative.

Although tillage practices could influence the magnitude of the water balance components to some extent, a low PSE was observed under all soil management practices. The work underlying this paper showed that cropping systems could be adjusted to precipitation patterns for better soil water use. Hence, a further task for the future is to determine the ideal cropping system at which desirable economic benefits can be maintained. Use of a fallow crop as peanut might be a good choice because of its high economic value and the benefit of legumes in the maintenance of soil organic N (Van Kessel and Christopher, 2000).

\section{Acknowledgements}

The research work was conducted in the framework of the project "Strengthening of the soil and water 
conservation research at Soil and Fertilizer Institute, Chinese Academy of Agricultural Sciences" and "Improving the capacity of the Soil and Fertilizer Institute (CAAS, China) for controlling nutrient losses by erosion and optimizing nutrient use efficiency in the loess belt of Northern China" which were funded by the Flemish Interuniversity Council, Belgium, to which we are greatly indebted. We are further grateful to Steven De Gryse, Tom Braeckman and Xiaobin Wang for their assistance in field installation of the equipment, soil sampling, monitoring, and analysis.

\section{References}

Baumhardt, R.L., Jones, O.R., 2002. Residue management and tillage effects on soil-water storage and grain yield of dryland wheat and sorghum for a clay loam in Texas. Soil Tillage Res. 68 (2), 71-82.

Cai, D.X., Jin, K., Wang, X.B., Hoogmoed, W.B., Oenema, O., Perdok, U.D., 2006. Conservation tillage for dryland farming in China. In: Proceedings of the 17th Conference on ISTRO, Kiel, Germany, pp. 1627-1634.

Cai, D.X., Wang, X.B., 2002. Conservation tillage systems for spring maize in the semihumid to arid areas of China. In: Stott, D.E., Mohttar, R.H., Steinhardt, G.C. (Eds.), Sustaining the Global Farm. Selected papers from the 10th International Soil Conservation Organization Meeting held May 24-29, 1999 at Purdue University and the USDA-ARS National Soil Erosion Research Laboratory, IN, USA, pp. 366-370.

Cantero-Martinez, C., O'Leary, G.J., Connor, D.J., 1999. Soil water and nitrogen interaction in wheat in a dry season under a fallowwheat cropping system. Aust. J. Exp. Agric. 39, 29-37.

Cornelis, W.M., Wu, H.J., Schiettecatte, W., Jin, K., Hartmann, R., Gabriels, D., Cai, D.X., 2004. Conservation tillage practices on a dryland winter wheat field in northern China: a soil-water balance study using a trime tube probe. Acta Agrophys. 4, 25-36.

Fabrizzi, K.P., Garcia, F.O., Costa, J.L., Picone, L.I., 2005. Soil water dynamics, physical properties and corn and wheat responses to minimum and no-tillage systems in the southern Pampas of Argentina. Soil Tillage Res. 81, 57-69.

Franzluebbers, A.J., 2002. Water infiltration and soil structure related to organic matter and its stratification with depth. Soil Tillage Res. 66, 197-205.

Gao, X.K., Wang, X.B., Wang, D.S., 1991. A study on tillage techniques for soil-water storage and conservation in rainfed wheat field. Chin. J. Agric. Res. Arid Areas 4, 1-9 (in Chinese).

Gicheru, P., Gachene, C., Mbuvi, J., Mare, E., 2004. Effects of soil management practices and tillage systems on surface soil water conservation and crust formation on a sandy loam in semi-arid Kenya. Soil Tillage Res. 75 (2), 173-184.

Halvorson, A.D., Black, A.L., Krupinsky, J.M., Merrill, S.D., Wienhold, B.J., Tanaka, D.L., 2000. Spring wheat response to tillage system and nitrogen fertilization within a crop-fallow system. Agron. J. 92, 288-294.

Hillel, D., 1998. Environmental Soil Physics. Academic Press, San Diego, CA, USA.

Holland, J.M., 2004. The environmental consequences of adopting conservation tillage in Europe: reviewing the evidence. Agric. Ecosyst. Environ. 103, 1-25.
Huang, M.B., Shao, M.G., Zhang, L., Li, Y.S., 2003. Water use efficiency and sustainability of different long-term crop rotation systems in the Loess Plateau of China. Soil Tillage Res. 72, 95-104.

Huang, Y.L., Chen, L.D., Fu, B.J., Huang, Z.L., Gong, E., 2005. The wheat yields and water-use efficiency in the Loess Plateau: straw mulch and irrigation effects. Agric. Water Manag. 72, 209-222.

Huang, M.B., Zhong, L.P., 2003. Evaluating the EPIC model to simulate soil water content of the Loess Plateau China. J. Exp. Bot. 54, 25-26.

Lafond, G.P., Boyetchko, S.M., Brandt, S.A., Clayton, G.W., Entz, M.H., 1996. Influence of changing tillage practices on crop production. Can. J. Plant Sci. 74, 641-649.

Le Houerou, H.N., 1984. Rain-use efficiency: a unifying concept in arid-land ecology. J. Arid Environ. 7, 213-247.

Leng, S.L., Han, S.F., 1996. Theory and technology on the water saving practices in the dryland of Northern China. China Agricultural Sciences Press, Beijing, pp. 149-160 (in Chinese).

Lenssen, A.W., Johnson, G.D., Carlson, G.R., 2007. Cropping sequence and tillage system influences annual crop production and water use in semiarid Montana, USA. Field Crops Res. 100, $32-43$.

Li, S., 2004. Chinese Dryland Agriculture. Chinese Press of Agriculture, Beijing, pp. 121-150 (in Chinese).

Liang, Y.L., Zhang, C.E., Guo, D.W., 2002. Mulch types and their benefit in cropland ecosystems on the Loess Plateau in China. J. Plant Nutr. 25 (5), 945-955.

Lipiec, J., Hatano, R., 2003. Quantification of compaction effects on soil physical properties and crop growth. Geoderma 116, 107-136.

Luk, Huang, S.W., 1991. Soil erosion and land management in the Loess Plateau Region, North China. Chin. Geography Environ. 3, $3-28$.

Lyon, D.J., Stroup, W.W., Brown, R.E., 1998. Crop production and soil water storage in long-term winter wheat-fallow tillage experiments. Soil Tillage Res. 49, 19-27.

Maesschalck, G., Verplancke, H., De Boodt, M., 1984. Water use and water use efficiency under different management systems for upland crops. In: International Rice Research Institute Workshop on Physical Aspects of Soil Management in Rice-based Cropping Systems, Manila, pp. 396-408.

McGarry, D., 2005. The current status of conservation agriculture in China. http://www.adb.org/projects/PRC_GEF_Partnership/current-status.pdf.

Mualem, Y., 1976. A new model for predicting the hydraulic conductivity of unsaturated porous media. Water Resour. Res. 12, 513-522.

Schiettecatte, W., Jin, K., Yao, Y., Cornelis, W.M., Lu, J., Wu, H., Cai, D., Verbist, K., Gabriels, D., Hartmann, R., 2005. Influence of simulated rainfall on physical properties of a conventionally tilled loess soil. Catena 64, 209-221.

Tanaka, D.L., Anderson, R.L., 1997. Soil water storage and precipitation storage efficiency of conservation tillage systems. J. Soil Water Conserv. 52, 363-367.

Van Genuchten, M.Th., 1980. A closed-form equation for predicting the hydraulic conductivity of unsaturated soils. Soil Sci. Soc. Am. J. 44, 892-898.

Van Kessel, C., Christopher, H., 2000. Agricultural management of grain legumes: has it led to an increase in nitrogen fixation? Field Crops Res. 65, 165-181.

Walkley, A., Black, I.A., 1934. An examination of the Degtjareff method for determining soil organic matter and a proposed 
modification of the chromic acid titration method. Soil Sci. Soc. Am. J. 37, 29-38.

Wang, W.M., 1994. Dryland Farming Technology in North China. China Agricultural Science and Technology Press, Beijing, pp. 167-192.

Wang, X.B., Cai, D.X., Hoogmoed, W.B., Oenema, O., Perdok, U.D., 2006. Potential effect of conservation tillage on sustainable land use: a review of global long-term studies. Pedosphere 16, 587595.

Wang, X.B., Cai, D.X., Jin, K., Wu, H.J., Bai, Z.G., Zhang, C.J., Yao, Y.Q., Lu, J.J., Wang, Y.H., Yang, B., Hartmann, R., Gabriels, D., 2003. Water availability for winter wheat affected by summer fallow tillage practices in slope dryland. Agric. Sci. China 2, 773-778. 